\title{
Information and Energy Policy Preferences: A Survey Experiment on Public Opinion about Electricity Pricing Reform in Rural India
}

\author{
Michaël Aklin* \\ NYU
}

\author{
Patrick Bayer ${ }^{\dagger}$ \\ Washington University
}

\author{
S.P. Harish $\ddagger$ \\ NYU
}

\author{
Johannes Urpelainen $\S$ \\ Columbia University
}

9 July 2014

\begin{abstract}
A common argument for the lack of economic reform in developing countries is popular opposition. If current economic policies are dysfunctional, could information about alternatives sway the voters? We examine if a simple argument emphasizing the need to increase electricity prices for improved supply can change public opinion in the case of India's power sector reforms. The evidence comes from a survey experiment in rural Uttar Pradesh, which is both India's largest state and has one of the lowest levels of household electrification. As expected, people respond to information about the relationship between electricity pricing, capacity investment, and reliability of supply by increasing their support for higher prices. However, no corresponding increase is observed for privatization of electricity generation. For external validity, we analyze an existing national survey on electricity privatization from 2004-2005, finding patterns that support our argument.
\end{abstract}

Keywords: electricity; power sector; survey experiment; investment; India; rural development. JEL Code: O13; Q48; Q58.

\footnotetext{
* Department of Politics, New York University, 19 West 4th Street, New York, NY 10012.

${ }^{\dagger}$ Corresponding author. Department of Political Science, Program in International \& Area Studies, Washington University in St. Louis, One Brookings Drive, St. Louis, MO 63130. Email: patrickbayer@wustl.edu. Phone: 314-9355810.

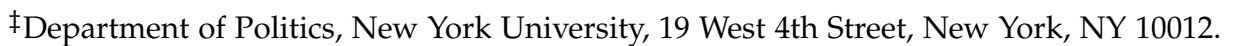

$\S$ Department of Politics, Columbia University, 420 West 118th Street, New York, NY 10027.
} 


\section{Introduction}

For decades, India has suffered from an inefficient power sector that frequently fails to generate the electricity that the country needs for economic growth and wellbeing. The situation is especially dire in rural areas. Not only are electrification rates low, but the electricity grid frequently fails to provide a reliable supply of power when people need it. The latest census data indicate that every third Indian remains without access to electricity even for basic household services (Government of India, 2011a), and in some major states such as Bihar the situation is much worse.

Why has India failed to improve reliable rural electricity supply? One popular hypothesis for India's failure to reform the power sector is popular opposition to increased electricity tariffs (i.e. pricing), especially among influential segments such as farmers who own electrified water pumps (Lal, 2006; Santhakumar, 2008). In this telling, large segments of the Indian population oppose higher electricity tariffs. Even if they are interested in the improved reliability of power supply, they may worry that the state's promise that reform improves service is not credible. As Lal (2006: 24) puts it, the state "has failed to carry credible assurances" that the reform will actually improve customer service. A related issue is the lack of capital investment by the private sector (Singh, 2006; Szakonyi and Urpelainen, 2013). While the lack of cash flow from consumers due to low prices is a central problem, it might be reduced if private companies invested in the power sector. While private utilities may also wish to increase tariffs, they could plausibly improve quality because their profits depend on the provision of a good service.

Is there any hope for change? Could new information about the potential benefits of reform sway the Indian public to support a financially sustainable power sector? If so, under what conditions? The provision of information is often assumed to be a key determinant of public opinion (Barabas and Jerit, 2010; Jerit and Barabas, 2006; Prior and Lupia, 2008; Alvarez and Brehm, 2002), but we know little about its role in individual preferences over energy issues and development policies more generally. We hypothesize that an argument emphasizing the direct effect of higher electricity tariffs on the reliability of supply will be powerful in India. Higher electricity tariffs improve the financial situation of the electricity suppliers, thus releasing funds for capacity investment. Improved capacity, in turn, allows a more reliable supply to customers. This goes against the conventional wisdom that people prefer low prices and reforms can only succeed "by stealth" (Jenkins, 1999; Varshney, 1998).

In answering this question, it is important to recall that pricing reform is not the same as privatization. In principle, public power generation companies can increase their electricity tariffs and invest the revenue in improved capacity and distribution. Since power sector privatization is politically controversial in India (Lal, 2006; Santhakumar, 2008), we distinguish between privatization and increased electricity tariffs. 
Even if privatization fails to garner public support, a pricing reform may prove popular. We separately investigate the effect of pro-reform information on support for pricing reform versus privatization.

To test the argument, we report empirical results from a survey experiment in rural Uttar Pradesh on building public support for higher electricity tariffs in India. The experiment was conducted on a convenience sample of 593 subjects in the Shahjahanpur district of Uttar Pradesh in the spring of 2013. This location of the experiment is interesting for several reasons. First, Uttar Pradesh has one of the lowest electrification rates in the country, with only $37 \%$ of households relying on grid electricity for lighting (Government of India, 2011a). Second, the quality of electricity supply is poor. On average, a household in Uttar Pradesh has about 9 hours of electricity per day; this number drops to 7 hours for households located in rural regions (Desai et al., 2007). Finally, the villages where the survey was conducted were electrified only a few months before the survey. Therefore, electricity is a salient topic and we have a relatively even split of electrified and unelectrified households in the sample.

The findings testify to the power of new information. Since the villagers consider power supply to be the government's responsibility, a clear majority of the sample opposes privatization of power generation, and our arguments have little effects on our respondents. However, once the positive relationship between higher electricity tariffs and improved service quality is explained, respondents strongly favor a price increase. Specifically, the information treatment significantly increases support for higher prices by 0.45 points, on average, on a $0-4$ response scale. Given that the treatment is a simple script with information, this treatment effect in the order of $10 \%$ is substantively important. Not only do people seem to understand and believe that higher prices encourage capacity investment, but this information was sufficiently powerful to create public support for price increases. This is all the more remarkable, given that $70 \%$ of our respondents already had an electricity connection and would have to pay higher prices.

Since the experiment was conducted on a convenience sample, it is important to conduct further analysis on the generalizability of the findings. To this end, we analyzed public opinion data on power sector reform supplied by Santhakumar (2008) in a national survey of India conducted in 2004-2005. This survey reflects public opinion about electricity privatization in 13 major Indian states, with Orissa excluded because privatization had already been implemented in 1996. We show that the patterns which our theory predicts can also be found in this data set. While opposition to privatization is strong, people who experienced increases in prices tended to be more favorable to further price increases, suggesting that they witnessed the improvement of electricity quality obtained by their contribution. Additionally, more educated individuals, who presumably are better informed about the benefits of cost recovery in pricing, are willing to pay higher tariffs. 
The article offers a dual contribution to the social sciences. First, we add to the body of literature on economic reform by showing that new information about the benefits of higher prices can have notable effects on public opinion. This complements the finding in Baker (2003) that people do support economic reforms if it is in their direct self-interest. We show that the lack of support for efficient economic reforms could simply reflect the public's lack of awareness of the benefits of the reform, as opposed to insistence on low prices and generous subsidies. Moreover, our finding on the importance of distinguishing between price increases and privatization suggests that conflating popular and unpopular elements of economic reform in public communication can dilute the effectiveness of new information.

Second, the findings have important implications for the politics of power sector reform in India. The role of popular opposition to electricity reform remains debated in the literature (Lal, 2006; Santhakumar, 2008). Our findings support Lal's (2006) view that while people do appreciate the benefits of enhanced power generation, they worry that the reforms may not deliver. This interpretation is warranted because the argument we tested does not require a complex implementation strategy by the state. Enhanced revenue allows increased capacity investment by the power sector, and this results in improved supply. Our argument goes against Jenkins's (1999) general argument that reforms in India often progress "by stealth." Our findings suggest that policymakers can build popular support for higher electricity tariffs and, in so doing, overcome entrenched interests.

A reform strategy that emphasizes these benefits, while downplaying privatization, could be effective, provided the challenges of regulatory reform are not forgotten (Dubash and Rao, 2008). This recommendation is in line with findings from a volume edited by Victor and Heller (2007) on power sector reforms in developing countries. The studies in that volume show that full privatization is rare outside the traditional industrialized countries, and most governments have opted for a "hybrid" solution of independent regulation without full privatization. Our findings suggest that this strategy could garner popular support among rural Indians.

The relevance of this argument, of course, depends on the role that the mass public plays in the politics of reform. In some cases, it could be that the mass public ultimately plays a relatively small role in determining reform. Some India experts have argued, for example, that the most influential opponents of power sector reform are interest groups such as utility employees and large farmers who own electric pumpsets (Lal, 2006). As Dubash and Rajan (2001: 3369) put it, "even though the constituents who stand most to gain from the supply of free electricity may be in the minority, they have appeared thus far to be those who maintain just enough swing power to capture the attention of most political parties." According to Jenkins (1999), governments can also avoid dealing with public opinion by implementing reforms "by 
stealth." More generally, the importance of public opinion for reforms may vary across countries, issue areas, and time (Varshney, 1998). Our findings indicate that governments may be able to generate public support among the mass public through information provision, but it remains to be seen if this can, in contexts like India, result in the kind of mass mobilization that would allow power sector reform to move forward.

\section{Electricity Provision in Rural India: Inadequate Supply, Lacking Reform}

In India, electricity provision has long suffered from major problems (Varshney, 1998; Rajan, 2000; Bhattacharya and Patel, 2007). According to the 2011 Census of India, one-half of rural India has no access to electricity at all (Government of India, 2011a). Worse, even if villages are electrified, the quality of service is low. Hansen and Bower (2003), for instance, report that it is common for farmers to have access to electricity only for 4-6 hours a day. To address the unequal development of urban and rural power supply, the Electricity Act ${ }^{1}$ and the Ministry of Power's Rural Electrification Policy ${ }^{2}$ were adopted to bring in private investment (Sharma, Nair, and Balasubramanian, 2005).

By unbundling State Electricity Boards (SEBs) and opening the power sector for private investors, policymakers wanted to promote access to and the quality of power supply (Singh, 2006). Since reducing energy poverty and improving the availability of electricity requires massive investment, attracting private power generation is often perceived as one way forward (Dubash and Rajan, 2001). With the largely bankrupt Indian SEBs in mind, whose total debt already amounted to about Rs 415 billion (US\$ 7 billion) in 2001 (Bhattacharya and Patel, 2007: 219), opening the electricity market to private players seems to kill two birds with one stone. Private electricity producers would relieve SEBs from investing into electricity generation, while forthcoming private investments would promote electricity access and improve service quality (Bacon and Besant-Jones, 2001).

Privatization of electricity markets differs across Indian states, with Orissa and Dehli having sought full privatization of production, transmission, and distribution early (Thakur, Deshmukh, and Kaushik, 2006). Other states have restricted privatization to power generation exclusively or shunned it altogether (Shukla et al., 2004; Bhattacharya and Patel, 2007; Dossani, 2004). Despite attempts to reform Indian electricity markets, major blackouts in recent years show that the reliability and quality of Indian power remains problematic.

The literature on India's power sector reforms reports that "disappointing results [of electricity market

\footnotetext{
${ }^{1}$ See http://cercind.gov.in/08022007/Act-with-amendment.pdf for the full text of the 2003 Electricity Act. Accessed on November 19, 2012.

${ }^{2}$ See http://www.powermin.nic.in/JSP_SERVLETS/internal.jsp for the Ministry of Power's website on rural electrification. Accessed on July 24, 2013.
} 
reform] have often resulted from a narrow focus on finance and cost recovery" (Williams and Ghanadan, 2006: 815). To reform electricity markets, "technical capacity, institutional legitimacy, and democratic legitimacy" (Dubash and Rao, 2008: 321) are needed in addition to economic resources. Solutions that ignore social and environmental dimensions will not be enough for transforming India's electricity market (Dubash, 2003; Yi-chong, 2006).

An alternative route for improving service quality of power supply in India is a comprehensive pricing reform without privatization. Failure to raise sufficient revenues prevents public investment into power generation, causing unreliable electricity provision. Therefore, a broader revenue base is needed. As long as low tariffs (especially agricultural), electricity theft, and unmetered use preclude SEBs from operating with reasonable profit margins (Joseph, 2010; Tongia, 2004), investment in badly needed power generation capacity will not be forthcoming. If tariffs were increased due to a pricing reform, SEBs would have more financial resources at their disposal to invest into transmission and distribution infrastructure.

Although pricing reform has potential to bring about considerable improvements in India's electricity markets, especially in terms of the reliability of service, policy reforms in democracies require the support of an electoral majority (Fernandez and Rodrik, 1991; Cukierman and Tommasi, 1998). Increasing electricity tariffs is itself not a popular policy, and the more so if artificially low electricity tariffs are used by incumbents to generate votes (Dubash and Rajan, 2001; Bhattacharya and Patel, 2007). However, even though electricity is provided at prices below competitive market rates, electricity consumers incur an implicit cost due to unreliable electricity service. As this cost is increasing over time (Bose et al., 2006), emphasizing the positive connection between service quality and higher tariffs may ultimately convince voters to favor higher electricity tariffs, thereby enabling electricity pricing reform. We now discuss the theoretical foundations of popular support and opposition to electricity pricing reform.

\section{Theory and Hypotheses}

Why do people in India oppose economic reform despite everyday experience with the inefficiencies of the current system? We present a theory that distinguishes between public opinion about two issues: privatization and the rational pricing of electricity based on cost recovery. For this, we define prices to be consistent with cost recovery when they enable electric utilities to invest in electricity generation, transmission, and distribution, so that reliable power supply could be ensured in the medium to long run. We argue that while the Indian people have severe reservations about privatization due to their concerns about unfairness and inequity, they are willing to accept the high tariffs implied by the rational pricing of electricity provided that they understand the relationship between tariffs and the quality of supply. 
To ensure a good fit between the theory and empirics, the argument is phrased in terms of the power sector. We also focus on the rural context, where electricity access is more severe than in urban areas, because that is where our data analysis is focused. Although the theory is focused on explaining the Indian situation, there are reasons to believe it applies more broadly. Electricity is a basic household commodity that greatly increases the convenience and productivity of everyday life (Cabraal, Barnes, and Agarwal, 2005; Dinkelman, 2011). Electricity enables basic lighting, mobile charging, radio or television, and thus paves the way for higher productivity and higher life quality. Therefore, households around the world should share the Indian population's interest in improved electricity supply.

\subsection{Centrality of State Responsibility}

Our first proposition is that rural villagers in India should have a strong preference for state intervention in the electricity sector. Building on the literature on economic reform, we argue that large segments of the population are concerned about privatization because they fear it prompts excessively high prices and inequitable supply. As Santhakumar (2003) argues, electricity privatization in India would induce power utilities to implement a strategy of cost recovery, adjusting electricity tariffs to ensure profits. If the Indian public believes that the strategy of cost recovery would result in significantly higher tariffs without any accompanying improvements in electricity services, then opposing privatization would be a rational position to hold. Following this logic, a state's failure to offer a reliable supply of electricity would be a smaller problem than the dual problem of higher electricity prices and problematic supply under privatization.

While this hypothesis has not been investigated in detail for the power sector, there is some evidence that the concern applies to privatization more generally. Denisova et al. (2012: 45) show that in 28 postcommunist countries, people commonly contest the legitimacy of past privatization rounds, believing "they failed to obtain their fair share from the initial round of privatization." Applied to the case of the Indian power sector, people would contest the legitimacy of a privatization strategy that they perceived to increase income inequality and to result in an income transfer from the large masses of poor to the wealthy owners of power utilities.

In the Indian context, the emphasis on the importance of state intervention is also a central element of much of the public debate. Perhaps most importantly, the Indian debate often emphasizes the idea of "inclusive growth" as the cornerstone of economic policy (Drèze and Sen, 2002). At least since Indira Gandhi's emphasis on poverty reduction as the key to economic policy, Indian politicians have campaigned on policies that redistribute wealth and ensure the inclusion of the poor in the economic growth process. 
One such policy would be the state ownership of basic infrastructure, which would allow the government to protect the poor from exploitative policies by private businessmen.

Based on these arguments, the first hypothesis from our theory is that people have a strong preference for state intervention in the electricity sector. If the Indian people worry about the distributive effects of privatization, they would not support a privatization process. The below hypotheses are written from the perspective of villagers with weak electricity supply but they also apply to unelectrified households in villages with electricity since they may expect a grid connection in the future.

Hypothesis 1 (state responsibility for electricity supply). People with weak electricity supply strongly prefer heavy state intervention in the electricity sector.

Conversely, we also expect people to generally oppose privatization of the power sector. Since privatization is the opposite of heavy intervention, a preference for state responsibility should also induce the Indian people to oppose privatization itself.

Hypothesis 2 (privatization). People with weak electricity supply strongly oppose privatization.

\subsection{Arguments for Higher Electricity Tariffs}

Having discussed state responsibility, we now turn to the second prong of our argument. In short, although people prefer state intervention, this need not mean they would not support higher electricity tariffs based on rational pricing, provided this allows improvements of supply. To begin the argument, we need to explain the relationship between electricity tariffs and power supply. Crucially for our argument, this relationship is simple. India's power utilities, which are responsible for power generation,

are continually on the verge of bankruptcy because they are unable to recover their costs from revenue (Santhakumar, 2008). If they could raise electricity tariffs and collect them more effectively, they could meet the investment gap in power generation. This would ensure that there is enough electricity in the system at peak times, especially at night.

The ties between energy supply, reliability, and price are contentious. An increase of price does not necessarily translate into better electricity supply. Nonetheless, our argument rests on two relatively uncontroversial claims. First, in India, electricity supply falls short of demand. This problem is well documented (Sanghvi, 1983; Ghosh, 2002). Second, this electricity gap can only be solved with consequential investments in better infrastructure (Thakur et al., 2005). In their current state, most Indian utilities are not in the position to make these investments. For instance, Ghosh (2002: 128) states that "most of the State Electricity Boards (SEBs) in India have been suffering from poor operational and financial performances. 
Lower electricity tariffs in the agricultural and domestic sector, which have been cross-subsidized by industrial sector, encourage the consumers for wasteful use of electricity." In view of this, it may come at no surprise that domestic electricity tariffs in states with successful power sector reforms, such as Gujarat or Maharashtra, were about 15\% and 36\% higher than the country's average domestic tariff in 2011-2012 (Government of India, 2011b: 165). Taken together, this suggests that pricing is part of the problem to the electrification problem. Better pricing is a necessary if not a sufficient condition.

Nothing in this proposition requires privatization. Even if people oppose privatization, they could still be willing to pay for improved service (Santhakumar, 2008; Bhattacharya and Patel, 2007). Therefore, an argument can be made that Indian states could solve their financial problems by raising tariffs. The revenue could be used in direct investments in power generation, which would mitigate the problem of poor and unreliable supply. While such a strategy would require careful regulation and feature a different set of challenges (Dubash and Rao, 2008), it would not depend on the politically unpopular act of privatization.

In essence, this simple argument would appeal to the self-interest of the Indian people. Instead of trying to argue for privatization, policymakers would simply propose higher prices in exchange for improved supply. Some interest groups, such as large farmers who use electricity for irrigation, might continue to oppose reform regardless (Lal, 2006; Joseph, 2010). However, those citizens whose specific concern would be privatization could change their view because their concern would be addressed. Provided that they would be willing to pay for better service, the proposition above would be a winning one for them. It is, of course, possible that governments increase tariffs first and then renege on the quality of electricity supply. However, governments in democracies generally want to provide public goods (independent of the political party in power) but are unable to do so if they cannot finance such initiatives. That said, we do not explicitly focus on commitment problems here.

This argument prompts three hypotheses. First, rural Indians should hold a strong preference against free supply, provided they understand it reduces service quality. Dubash and Rajan (2001: 3369), for instance, find that "it has even been reported that there is considerable popular opposition among the rural poor to provide free electricity to farmers...Also, since the quality of power actually delivered to farmers has for long been extremely poor, it is widely accepted that most farmers are likely to prefer metered and priced reliable electricity to unmetered free (or low-tariff) unreliable electricity." Our argument is based on exactly this idea that people value good quality, which means that they should be opposed to a free supply of power if they understand the negative effects of free supply on service quality.

Hypothesis 3 (free supply and service quality). People with weak electricity supply strongly oppose free supply 
if they understand it reduces service quality.

Most centrally, we expect new information about the importance of electricity tariff increases for better supply to be effective in swaying public opinion. A vast and diverse literature contends that information should play a key role in policy preferences. In fact, it is generally accepted that a democracy requires well-informed citizens to function properly (Lippman, 1922). However, in practice people are poorly informed about many important issues, even in countries with modern education systems, such as the United States (Alvarez and Brehm, 2002). New information can thus be expected to have a considerable effect in shifting public opinion over public goods. For instance, trade scholars argue that providing information to voters will unlock support for free trade: once individuals are made aware of the benefits of free trade, the argument goes, they will support it (Hainmueller and Hiscox, 2006). Closer to our argument, researchers argue that the provision of information shapes energy and environmental preferences, both in industrialized and developing countries (Aklin and Urpelainen, 2013; Aklin et al., 2013). Similarly, Levine et al. (1995) underscore the importance in the aftermath of the first oil crisis in 1973 of information programs about energy efficiency on consumer behavior. The rationale is that individuals do not necessarily know about the consequences of the status quo, nor are they always aware of the existence of alternative possible outcomes.

A simple explanation for why increased electricity tariffs benefit service quality should tilt public opinion toward support for higher prices.

Hypothesis 4 (information, tariffs, and investment). People with weak electricity supply become more supportive of higher electricity tariffs if the relationship between revenue and service quality is explained.

Given that electrical power is often framed as a fundamental right, we can also scrutinize the public's willingness to pay for a good service by examining how their opinion reacts to power being framed as a universal right. If we are right to argue that people prefer state responsibility for the power sector, then another argument that could sway their opinion is one based on a rights framing. When electricity is framed as a universal right, Indians could be more willing to accept price increases because adequate supply is a key component of state responsibility.

Hypothesis 5 (rights, tariffs, and investment). People with weak electricity supply become more supportive of higher electricity tariffs if power is framed as a universal right.

Note that these hypotheses do not compete with each other. Both new information and a rights argument could prove effective, and the relative effectiveness of the arguments is ultimately an empirical question. 


\section{First Test: Experimental Evidence from Rural Uttar Pradesh}

To empirically test the hypotheses, we implemented a survey experiment in two villages, Toni and Chhite, of the Shahjahanpur district in rural Uttar Pradesh. Uttar Pradesh is an excellent site for our theoretical arguments. It is India's largest state, with close to 200 million inhabitants. The state electricity sector has not been privatized, though generation has been unbundled from transmission and distribution, and the supply-demand gap is acute. Recent census data from 2011 also shows that every third rural dweller has no access to electricity at all (Government of India, 2011a). Furthermore, survey data shows that even when electricity is available, access remains poor. An average household in Uttar Pradesh has 9 hours of electricity per day, and the situation is even worse for an average rural household: the latter only has, on average, 6 hours of electricity per day (Desai et al., 2007).

We selected the Shahjahanpur district and the two villages in focus to ensure that we would have both electrified and unelectrified households, while electricity supply would be poor. According to data collected in 2008 by the Indian Council of Social Science Research, electrification in the Shahjanpur is particularly low, with $15 \%$ of households reporting having access to electricity. ${ }^{3}$ The two villages had been electrified in the fall of 2012, or 3-6 months before we conducted our surveys. While it is possible that the prior lack of electricity in these villages were because of state subsidies in other parts of Uttar Pradesh, the electrification rate is as high as $70 \%$ due to a recent electrification effort in the sample (though about half of the connections are illegal). The electrified households are also concerned with both the reliability and the price of electricity.

The experiment was conducted by the Mass Oriented Research and Social Elevation Lab (MORSEL) in February-May 2013, with a total of 593 households interviewed. The households were randomly chosen from the 2011 census household list for the two villages. So, while the choice of the two villages was based on convenience, the sample within those two villages was random. Of the 593 households interviewed, for 401 subjects we also conducted a thorough baseline survey one week before the experiment was implemented. Unfortunately, we did not have the resources to conduct such a survey for all of the subjects. All interviews were conducted in the local dialect of Hindi by experienced enumerators from Uttar Pradesh. The survey company has conducted dozens of surveys and field experiments in India for academic researchers and all of their enumerators are fully trained and experienced. One of the authors accompanied the survey team to the field for training and initial interviews in January-February 2013. The survey team was trained for a full day in Lucknow and one of the authors oversaw the initial interviews

\footnotetext{
3"Executive Summary Shahjahanpur District." 20Shahjahanpur .pdf. Accessed on March 18, 2014).

See http://www.icssr.org/Executive $\% 20$ Summary $\% 20-\%$
} 
the next day. During the training and pilot, the entire survey questionnaire was evaluated and revised for accuracy. Moreover, every enumerator who participated in the study did at least one mock or real interview of a subject under the supervision of one of the authors.

For our two study villages, electrification rates closely mirror the state average as out of 401 survey households 282 reported to have access to electricity, still leaving about $30 \%$ of the households unelectrified. Electricity tariffs for domestic use in Uttar Pradesh were 348.03 Paise/kWh in 2011-2012, compared to an average tariff of 321.82 Paise/kWh across all Indian states (Government of India, 2011b: 165). Despite recent improvements in electrification, rural villagers are aware of unreliable electricity supply. On average, households have electricity only available for 14 hours a day, ranging from as little as one hour a day to almost 24 hours. Similarly, $68 \%$ of 100 households for which we have data mention that they experienced an electricity outage during the last 24 hours, and satisfaction levels with household lighting are stated to be low as well, with the majority of households being "somewhat dissatisfied" or "very dissatisfied." Anecdotal evidence from our field work is also suggestive of the respondents' concern for quality of electricity supply. For instance, one male respondent in his fifties who had an electricity connection bitterly complained that the government had promised to electrify the villages for years, but now failed to provide practically any electricity. Power was only available for a few hours in the afternoon when he was often not at home. At night, when power would have been needed, it was rarely available. This evidence is important as it ensures that our analysis is not misplaced. The connection between electricity tariffs and reliable supply is key also to recently electrified villagers.

The basic idea of our experimental test was to elicit interviewees' responses on four outcome measures related to electricity markets and electricity pricing in Uttar Pradesh as a function of information provided by us. While we explain our informational treatments in greater detail below, we randomly assigned each interviewed household to either a control or one of two treatment groups. The two treatment conditions are different in that they either emphasize that there is a trade-off between low electricity prices and an ensuing lack of reliable electricity services (T1) or the notion that electricity is a fundamental right that has to be provided by the state government of Uttar Pradesh (T2). In view of the theoretical arguments derived above, the first two hypotheses about the central role of state intervention for the provision of electricity are purely correlational. Our two treatments, then, aim at putting the three last hypotheses about higher electricity tariffs to a rigorous experimental test. The first treatment leverages the connection between increased electricity tariffs and service quality, which provides us with an empirical handle to directly get at Hypotheses 3 and 4. The second treatment uses a universal rights framing and is thus a direct experimental test of Hypothesis 5. 
For assessing the empirical effects of these two treatments on outcomes in our survey experiment, we run two types of analyses. First, we calculate simple pairwise t-tests to test for mean differences in interviewees' responses across experimental conditions. Second, we apply regression techniques with the following regression equation

$$
\text { Outcome }_{i}=\alpha+\beta_{1} \mathrm{~T}_{i}+\beta_{2} \mathrm{~T}_{i}+\delta_{1} \text { Interviewer }_{j}+\delta_{2} \text { Village }_{k}+\varepsilon_{i},
$$

where $\beta_{1}$ and $\beta_{2}$ are the regression coefficients of the dummy variables of the two treatment conditions, $\delta_{1}$ and $\delta_{2}$ denote interviewer and village fixed effects, and $\alpha$ and $\varepsilon_{i}$ are the regression intercept and the individual error term, respectively. Given our five hypotheses above, our main interest lies in coefficients $\beta_{1}$ and $\beta_{2}$, which capture the effect that a particular treatment condition has on the outcome variable relative to the control condition as a baseline. In contrast to a pairwise t-test between the means of the control and the first treatment group, $T 1$, for instance, the $\beta_{1}$ coefficient assesses the effect of being in this experimental condition net of the effect that being in treatment group T2 has. Positive $\beta$ coefficients denote higher expected means than in the control group, while lower $\beta$ coefficients translate into smaller expected mean outcomes than in the baseline category.

\subsection{Treatments}

As mentioned above, the 593 respondents are randomly assigned to any of the following three groups: control group $(\mathrm{N}=198)$, treatment group T1 $(\mathrm{N}=198)$, and treatment group T2 ( $=197)$. Table 1 below summarizes the three experimental conditions and provides the exact wording of the informational treatments which we administered. Survey respondents assigned to the control group did not receive any informational treatment, whereas households in the first treatment group were informed that unreliable electricity services are due to low electricity tariffs, which make investment in electricity infrastructure impossible. In contrast to this price reform treatment, households assigned to the second treatment were primed that access to electricity is often argued for to be a fundamental right, which is to be provided by local governments.

\section{[Table 1 about here.]}

While the fundamental rights treatment is supposed to increase the respondents' likelihood to see electricity provision fall into a local government's domain as compared to private providers, the price increase treatment pinpoints the trade-off between electricity prices and reliability of electricity services. The latter 
treatment, thus, puts the claim that poor rural villagers are utterly opposed to increasing electricity tariffs no matter what to a strong empirical test.

\subsection{Outcome Measures}

For measuring outcomes, we ask the respondents in our survey experiment to answer four questions, which are posed right after the experimental treatment (no treatment for control group, price reform treatment for T1 group, or fundamental rights treatment for T2 group) was administered. The outcome measures are summarized in Table 2.

[Table 2 about here.]

First, we ask respondents if free supply of electricity to rural households should not be allowed if this increases the reliability of supply. Second, we ask whether the local Government of Uttar Pradesh should invest in improved electricity generation capacity even if this comes with an increase in electricity tariffs. Third, we want to know if electricity markets should be privatized and, finally, if electricity is a commodity that the state should provide to all Indians. All answers are recorded on a 0-4 scale, where higher numbers denote stronger agreement, ranging in equal steps from "strongly disagree," coded as zero, to "strong agree," coded as 4 . To clarify our expectations, a positive coefficient $\beta_{1}$ in regression models with Outcomes 1 and 2 as dependent variables constitute support for Hypotheses 3 and 4, while a positive coefficient $\beta_{2}$ suggests empirical evidence in favor of the fifth hypothesis in regressions with Outcome 4 as the dependent variable.

\section{Findings}

In this findings section, we discuss and detail our results. For this, we present summary statistics and simple t-tests first, which already provide strong support in favor of our hypotheses. Additionally, we strengthen the empirical evidence of our theoretical argument by also discussing results based on regression analysis techniques.

\subsection{Descriptive Statistics}

A major advantage of using an experimental research design is that simple descriptive statistics and correlation matrices can already be considered first good indicators as to whether our theory finds support in the data. From the summary statistics, presented in Table 3, we can already get a clear initial glimpse of what preferences of rural villagers in Uttar Pradesh look like. In fact, our results can be interpreted as tentative support for Hypotheses 1 to 3 . With higher values on the outcome variables translating into 
higher levels of approval, we find that higher electricity prices are strongly supported if this implies better quality of electricity supply (Outcome 1). Even though support for governmental investment in electricity generation capacity is more modest (Outcome 2), a mean of 2.62 still indicates that a majority of our respondents tend to be supportive of this proposition. Both findings align with Hypothesis 3 from above which argues that Indian people's support for free electricity supply is low once they are informed that this has negative consequences for the reliability with which power is supplied.

[Table 3 about here.]

The results on who should provide electricity (the state or the private sector), and thereby testing Hypotheses 1 and 2, are clear: while privatization and electricity being supplied by markets (Outcome 3) is essentially disapproved of by interviewees (mean response of 0.82 ), there is almost universal support (mean of 3.93) for the claim that electricity is to be provided for all Indians by the state (Outcome 4). This is consistent with our first two hypotheses on the centrality of state responsibility. Even though, we cannot draw any inferences as to the effectiveness of our treatments from the summary statistics alone, these descriptives nonetheless help ascertain the validity of our first three hypotheses.

To further illustrate basic electricity preferences in our sample, the correlation matrix, which is shown in Table 4, reveals that there is a strong, and positively significant bivariate correlation between Outcomes 1 and 2. This correlation suggests that respondents who oppose free electricity provision as they understand the negative relationship with service quality are at the same time more supportive of government investment in electricity infrastructure. This link is important as it testifies to at least some people's awareness of the connection between governmental investment, reliable electricity supply, and higher electricity tariffs. Without seeking to unduly overstate this bivariate correlation, we nonetheless emphasize it as it lends plausibility to the causal mechanism proposed in our argument.

\section{[Table 4 about here.]}

\subsection{Simple Statistical Tests}

Before presenting regression results, though, we implemented several pairwise t-tests to statistically test for simple differences in means across treatment and control groups, separated by outcome variable. The results are shown in Table 5. Compared to our results based on summary statistics alone, t-tests allow us to examine whether the administered treatments had some effects in systematically changing respondents' electricity preferences. 
[Table 5 about here.]

From the results, we see that statistically significant differences in means across groups are found only for our second outcome variable. Hence, respondents from the price reform treatment (T1) and the fundamental rights treatment (T2) have significantly higher agreement levels than the control group at p-values of $p<0.001$ and $p<0.035$, respectively. This provides support for Hypotheses 3 and 4, which emphasize that respondents' willingness to pay more grows as the connection between tariffs and service reliability is recognized. As there is no statistically significant difference between the means from the two treatment conditions, there seems to be no differential effect from either appealing to a universal rights or pricing reform argument.

For all the other outcome variables, we cannot identify any effects of our informational treatments. The means across our experimental groups printed in Table 5 suggest, however, that no such differences can be detected because the levels of agreement are very similar across the three groups, at least without controlling for other confounding variables. The largest drawback of using simple t-tests alone is that they only allow assessing mean differences unconditional on any control variables. To address this point, we now turn to results from regression analysis.

\subsection{Regression Results}

We report regression results separately for each outcome variable, shown in Tables 6 to 9, which are all identical in structure. Models (1) and (2) report results from linear least squares estimation, whereas Models (3) and (4) use ordered probit as estimation technique to account for the non-normal distribution of our dependent variable and its clear rank ordering. For each of these two groups of models, the first model specification only includes the treatment dummies, while the second model is estimated with both interviewer and village fixed effects. By including fixed effects we make sure that our findings are not driven by potential village differences across the two villages, Chhite and Toni, in which we conducted the survey experiment. For similar reasons, we also estimate models with interviewer fixed effects to account for potential differences akin to the eight interviewers active in the field for our study.

In the supplementary appendix we also present additional model specifications which include up to four control variables. Importantly, these controls on status of electrification, free market attitudes, and socio-economic household characteristics were collected as part of a household survey approximately one week prior to administering treatment and are used to increase the power of our analysis. As we had only resources to conduct full surveys for 401 households out of 593 to which treatment was administered, we prefer to present the more parsimonious models here. This decision is innocuous, as our estimation 
results are shown to be qualitatively identical when we apply a covariate control strategy.

For our first outcome variable, it seems that the second, universal rights treatment has virtually no effect on interviewees' responses on whether electricity should not be provided for free. The effects are small in size, are not robust across specifications, and lack statistical significance at any conventional levels. For the pricing reform treatment, the estimated coefficients are larger in size and are consistently estimated to be positive. With standard errors of about the same size as the coefficient itself, the estimated effects fail to be statistically significant. As already discussed above, this weak finding is largely indebted to the similarity in average response levels across the control and treatment groups. If between-group differences are minuscule, disentangling treatment effects is difficult given our moderate sample size.

\section{[Table 6 about here.]}

Both treatments have strong effects on the second outcome variable. The second treatment is statistically significant at least at the $10 \%$ significance level across all models, which we take as support for Hypothesis 5. What is more, the pricing reform treatment is highly statistically significant across all four models, indicating positive empirical evidence for our third and fourth hypotheses. Effect sizes are non-trivial, as receiving this informational treatment increases the response level by 0.45 according to Model (1), for instance. Given the 0-4 scale for our response variables, the informational treatment implies a $10 \%$ change on this scale.

\section{[Table 7 about here.]}

When turning to the question on whether electricity markets should be privatized, the universal rights treatment has again a consistently positive effect across all models, suggesting higher preferences for free markets once the treatment is administered. As these effects lack statistical significance, though, we caution against a too literal interpretation. Similar positive effects are found for the price reform treatment; notwithstanding that these coefficients are statistically significant in all models and provide tentative support for Hypotheses 3 and 4, the coefficient is only about half the size when compared to our second outcome measure. An additional analysis, which is shown in the supplementary appendix, also suggests that the treatment effect of the price reform treatment loses statistical significance once we control for a respondent's preference for free markets. This accords well with the positive correlation between our third outcome measure and the control variable $(r=0.109, p \leq 0.10)$.

[Table 8 about here.] 
Finally, we find positive but statistically insignificant coefficients for both treatments when considering the respondents' preference for electricity being provided by the state. As discussed earlier, with means of 3.90 in the control group and 3.94 in the treatment groups on a $0-4$ scale, it is impossible for the treatment to override any of the villagers' deeply rooted preferences.

\section{[Table 9 about here.]}

The results provide support in favor of the hypotheses. First, there is strong support in favor of electricity being provided by the state, rather than private firms (Hypotheses 1). Privatization is highly opposed by villagers in rural Uttar Pradesh (Hypothesis 2). Moreover, once people understand that higher electricity tariffs are needed to enable SEBs to invest in electricity generation capacity, which allows more reliable electricity provision, the respondents increasingly support pricing reform. The highest priority for most of the surveyed villagers, it seems, is reliable power supply. There is public support in favor of reform of the Indian electricity sector, once the rationale for higher prices is explained properly. New information about the link between electricity tariffs and service quality creates public support for reform (Hypotheses 3 and 4).

\section{Evidence for External Validity: A National Survey of India, 2004-2005}

The main strength of the experimental approach is internal validity. Since we randomized our treatment, causal effects are properly identified and there is little need to worry about omitted variable bias or endogeneity. However, the external validity of a survey experiment conducted in a small sample in two villages may raise some concerns (Barabas and Jerit, 2010). Fortunately a closely related national survey from the years $2004 / 2005$ is available. Santhakumar (2008) analyzed social opposition to electricity privatization in the aftermath of the 2003 Electricity Act of India in 13 major Indian states. While his survey does not contain the exact treatments we are interested in, many of the survey questions are nonetheless relevant. Therefore, we use the Santhakumar (2008) data to verify the external validity of our results.

The Santhakumar (2008) data contain fairly detailed information about the views and preferences of people who already have an electricity connection ( $81 \%$ of the sample), while only a few questions were posed to unelectrified households (19\% of the sample). In total, his team conducted 6,241 interviews. Throughout the analysis, we clearly indicate if the question was presented to the entire sample or only electrified households.

To begin with, consider people's perceptions about electricity privatization. Consistent with our expectations, opposition to privatization was prevalent. Only $17 \%$ of the sample supported privatization, 
while $31 \%$ expressed a strong preference against privatization. The rest were either indifferent or chose the "do not know" option. This seems to be largely consistent with our first two hypotheses.

Willingness to pay for improved service quality was also high overall. When inquired about willingness to pay a higher price for electricity, $40 \%$ said they were in favor of the proposition. According to our theory, people should become more willing to pay a higher price if they understand the benefits of higher electricity prices. Strongly suggestive of this pattern is the fact that $45 \%$ of people whose electricity tariff has increased during the past year support higher prices, while only $41 \%$ do so if their tariff has not increased. The 2-tailed pairwise t-test also indicates that this difference is statistically significant at the $p<0.05$ level $(t=2.36)$. As expected, the experience with higher tariffs seems to create support for higher prices, which nicely aligns with our third hypothesis.

Finally, education increases support for higher prices. Since education is positively correlated with awareness and access to information about environmental and energy issues, this is consistent with our general theoretical framework (Aklin et al., 2013). In Table 10, we regress the binary indicator for willingness to pay higher prices on years of education and a variety of control variables. In particular, we control for respondent characteristics, such as age, sex, and whether the respondent is working in agriculture. At the household level, we include covariates on household assets to proxy for household wealth and whether the household received government subsidies. We estimate linear probability models as well as logit models with robust standard errors and district fixed effects. The education effect is positive and highly statistically significant across all six models. As interpretation is easier in OLS models, in the simpler Model (2) without controls, each year of additional education increases willingness to pay for higher prices by about $0.7 \%$ points, and this effect only drops slightly below half a percentage point in the full model. In substantive terms, this effect is non-trivial as changing the education variable from its lowest value (0 years of schooling) to its highest value (21 years of schooling), Model (3) suggests that willingness to pay rises by about $9 \%$ points.

[Table 10 about here.]

To summarize, the Santhakumar (2008) data establish the following points. First, there is strong opposition to privatization. Second, willingness to pay higher prices for increased supply depends on prior experience with electricity tariff increases. Finally, willingness to pay grows with additional education.

\section{Conclusion}

Economic reforms are politically controversial, and the available evidence shows that the public in many developing countries is deeply suspicious of the liberalization of economic policy (Stokes, 1996; Santhaku- 
mar, 2008; Denisova et al., 2012). In a democratic setting, elites interested in promoting reform must argue for the merits of the policy change. This article has investigated the effectiveness of rational economic arguments in the promotion of such a policy.

The Indian power sector offers an excellent setting for answering this question. There is a clear consensus among experts that the Indian power sector is unable to produce enough electricity to meet the needs of the population, and the root of the problem is in the woeful finances of the power utilities. Therefore, a pricing reform promises large payoffs. If power utilities can collect enough revenue to cover their costs, their willingness and ability to pay for power generation capacity grows. Along with investment in transmission and distribution, this growth effectively mitigates outages and other problems of supply.

To test the effect of new information on preferences, we conducted a survey experiment in rural Uttar Pradesh. The main finding was that information in favor of reform is a powerful determinant of public opinion. Given this, it is indeed surprising that information as a policy instrument to build public support for reform remains currently unused by the regulatory agency in Uttar Pradesh. Compared to the control group, subjects who were given a simple information package about the importance of higher prices for reliance were considerably more supportive of price increases. At the same time, though, support for privatization did not increase. This suggests that people in rural Uttar Pradesh consider the state to be responsible for power generation, but at the same time they are willing to pay a fee for the service. The positive, if weaker, effect of a rights treatment further strengthens this interpretation.

The findings have important implications for scholarship on economic reform. If new information about the benefits of reform shapes public opinion, the question remains why they are not having a larger effect on policy. One possibility is that politicians offering such arguments face difficulties reaching their constituencies or must compete with alternative arguments (Aklin and Urpelainen, 2013). Future research should investigate the vulnerability of pro-reform messages to challenges, which could be equally powerful, from the anti-reform lobby. As discussed in the introduction, one should also recall that the mass public does not always play a major role in the politics of economic reform. Some next steps for this research program would be to identify the conditions under which public opinion does play a decisive role in the politics of reform and when new information works. These caveats notwithstanding, our results provide some hope for reform-oriented governments worried about the public legitimacy of their efforts. 


\section{Acknowledgements}

We thank the Institute for Social and Economic Research and Policy (ISERP) at Columbia University for financial support and the Council on Energy, Environment and Water (CEEW) in New Delhi for research support. We thank the Mass Oriented Research and Social Elevation Lab (MORSEL) for conducting the surveys. We are grateful to seminar audiences at Columbia University and CEEW for their thoughts. Patrick Bayer gratefully acknowledges funding from the German Academic Exchange Service (DAAD) for a postdoctoral fellowship at Washington University in St. Louis. We are grateful to Catalina Angel for careful proofreading of the manuscript. 


\section{References}

Aklin, Michaël, and Johannes Urpelainen. 2013. “Debating Clean Energy: Frames, Counter Frames, and Audiences." Glob Environ Chang 23 (5): 1225-1232.

Aklin, Michaël, Patrick Bayer, S.P.Harish, and Johannes Urpelainen. 2013. “Understanding Environmental Policy Preferences: New Evidence from Brazil." Ecol Econ 96: 28-36.

Alvarez, R. Michael, and John Brehm. 2002. Hard Choices, Easy Answers: Values, Information, and American Public Opinion. Princeton: Princeton University Press.

Bacon, R.W., and J. Besant-Jones. 2001. "Global Electric Power Reform, Privatization, and Liberalization of the Electric Power Industry in Developing Countries." Annu Rev Energ Env 26: 331-359.

Baker, Andy. 2003. "Why Is Trade Reform so Popular in Latin America? A Consumption-Based Theory of Trade Policy Preferences." World Polit 55 (3): 423-455.

Barabas, Jason, and Jennifer Jerit. 2010. "Are Survey Experiments Externally Valid?" Am Polit Sci Rev 104 (2): $226-242$.

Bhattacharya, Saugata, and Urjit R. Patel. 2007. "The Power Sector in India: An Inquiry into the Efficacy of the Reform Process." India Policy Forum 4 (1): 211-283.

Bose, Ranjan Kumar, Megha Shukla, Leena Srivastava, and Gil Yaron. 2006. "Cost of Unserved Power in Karnataka, India." Energ Policy 34 (12): 1434-1447.

Cabraal, Anil R., Douglas F. Barnes, and Sachin G. Agarwal. 2005. "Productive Uses of Energy for Rural Development." Annu Rev Environ Resour 30: 117-144.

Cukierman, Alex, and Mariano Tommasi. 1998. "When Does It Take a Nixon to Go to China?" Am Econ Rev 88 (1): 180-197.

Denisova, Irina, Markus Eller, Timothy Frye, and Ekaterina Zhuravskaya. 2012. "Everyone Hates Privatization, But Why? Survey Evidence from 28 Post-Communist Countries." J Comp Econ 40 (1): 44-61.

Desai, Sonalde, Amaresh Dubey, B.L. Joshi, Mitali Sen, Abusaleh Shariff, and Reeve Vanneman. 2007. "India Human Development Survey (IHDS)." University of Maryland and National Council of Applied Economic Research.

Dinkelman, Taryn. 2011. "The Effects of Rural Electrification on Employment: New Evidence from South Africa." Am Econ Rev 101 (7): 3078-3108.

Dossani, Rafiq. 2004. "Reorganization of the Power Distribution Sector in India." Energ Policy 32 (11): 1277-1289.

Drèze, Jean, and Amartya K. Sen. 2002. India: Development and Participation. New York: Oxford University Press. 2nd Edition.

Dubash, Navroz K. 2003. "Revisiting Electricity Reform: The Case for a Sustainable Development Approach." Util Policy 11 (3): 143-154.

Dubash, Navroz K., and D. Narasimha Rao. 2008. "Regulatory Practice and Politics: Lessons from Independent Regulation in Indian Electricity." Util Policy 16 (4): 321-331.

Dubash, Navroz K., and Sudhir Chella Rajan. 2001. "Power Politics: Process of Power Sector Reform in India." Econ Polit Weekly 36: 3367-3390. 
Fernandez, Raquel, and Dani Rodrik. 1991. "Resistance to Reform: Status Quo Bias in the Presence of Individual- Specific Uncertainty." Am Econ Rev 81 (5): 1146-1155.

Ghosh, Sajal. 2002. "Electricity Consumption and Economic Growth in India." Energ Policy 30 (2): 125 129.

Government of India. 2011a. "2011 Census Report, Houselisting and Housing Census Data Highlights." http://www. censusindia.gov.in/2011census/hlo/hlo_highlights.html.

Government of India. 2011b. "Annual Report on the Working of State Power Utilities and Electricity Departments, 2011-2012." See http://econpapers.repec.org/paper/esswpaper/id_3a4817.htm. Accessed March 22, 2014.

Hainmueller, Jens, and Michael J. Hiscox. 2006. "Learning to Love Globalization: Education and Individual Attitudes Toward International Trade." Int Organ 60 (2): 469-498.

Hansen, Christopher J., and John Bower. 2003. "Political Economy of Electricity Reform: A Case Study in Gujarat, India." Oxford Institute for Energy Studies Working Paper.

Jenkins, Rob. 1999. Democratic Politics and Economic Reform in India. New York: Cambridge University Press.

Jerit, Jennifer, and Jason Barabas. 2006. "Bankrupt Rhetoric: How Misleading Information Affects Knowledge about Social Security." Public Opin Quart 70 (3): 278-303.

Joseph, Kelli L. 2010. “The Politics of Power: Electricity Reform in India.” Energ Policy 38 (1): 503-511.

Lal, Sumir. 2006. "Can Good Economics Ever Be Good Politics? Case Study of India's Power Sector." World Bank Working Paper 83.

Levine, Mark D., Jonathan G. Koomey, Lynn Price, Howard Geller, and Steven Nadel. 1995. "Electricity End-Use Efficiency: Experience with Technologies, Markets, and Policies Throughout the World." Energy 20 (1): 37-61.

Lippman, Walter. 1922. Public Opinion. New York: Macmillan.

Prior, Markus, and Arthur Lupia. 2008. “Money, Time, and Political Knowledge: Distinguishing Quick Recall and Political Learning Skills." Am J Polit Sci 52 (1): 169-183.

Rajan, Thillai A. 2000. "Power Sector Reform in Orissa: An ex-post Analysis of the Causal Factors." Energ Policy 28 (10): 657-669.

Sanghvi, Arun P. 1983. "Optimal Electricity Supply Reliability Using Customer Shortage Costs." Energ Econ 5 (2): 129-136.

Santhakumar, V. 2003. "Impact of Distribution of Costs and Benefits of Non-Reform: Case Study of Power Sector Reforms in Kerala between 1996 and 2000." Econ Polit Weekly 38 (2): 147-154.

Santhakumar, V. 2008. Analysing Social Opposition to Reforms: The Electricity Sector in India. Thousand Oaks: Sage.

Sharma, D. Parameswara, P.S. Chandramohanan Nair, and R. Balasubramanian. 2005. "Performance of Indian Power Sector During a Decade under Restructuring: A Critique." Energ Policy 33 (4): 563-576. 
Shukla, P.R., Debashish Biswas, Tirthankar Nag, Amee Yajnik, Thomas Heller, and David G. Victor. 2004. "Impact of Power Sector Reforms on Technology, Efficiency and Emissions: Case Study of Andhra Pradesh, India." Stanford University, Program on Energy and Sustainable Development Working Paper 20.

Singh, Anoop. 2006. "Power Sector Reform in India: Current Issues and Prospects." Energ Policy 34 (16): 2480-2490.

Stokes, Susan C. 1996. "Public Opinion and Market Reforms: The Limits of Economic Voting." Comp Polit Stud 29 (5): 499-519.

Szakonyi, David, and Johannes Urpelainen. 2013. "Electricity Sector Reform and Generators as a Source of Backup Power: The Case of India." Energy for Sustainable Development 17 (5): 477-481.

Thakur, Tripta, S.G. Deshmukh, and S.C. Kaushik. 2006. "Efficiency Evaluation of the State Owned Electric Utilities in India." Energ Policy 34 (17): 2788-2804.

Thakur, Tripta, S.G. Deshmukh, S.C. Kaushik, and Mukul Kulshrestha. 2005. "Impact Assessment of the Electricity Act 2003 on the Indian Power Sector." Energy Policy 33 (9): 1187-1198.

Tongia, Rahul. 2004. "The Political Economy of Indian Power Sector Reforms." Stanford University, Program on Energy and Sustainable Development Working Paper 4.

Varshney, Ashutosh. 1998. "Mass Politics or Elite Politics? India's Economic Reforms in Comparative Perspective." J Policy Reform 2 (4): 301-335.

Victor, David G., and Thomas C. Heller, eds. 2007. The Political Economy of Power Sector Reform: The Experiences of Five Major Developing Countries. New York: Cambridge University Press.

Williams, J.H., and R. Ghanadan. 2006. "Electricity Reform in Developing and Transition Countries: A Reappraisal." Energ 31 (6-7): 815-844.

Yi-chong, Xu. 2006. "The Myth of the Single Solution: Electricity Reforms and the World Bank." Energ 31 (6-7): 802-814. 
Summary of experimental conditions

\begin{tabular}{|c|c|}
\hline Experimental condition & Treatment \\
\hline Control group & No treatment text assigned. \\
\hline Treatment 1 (T1, pricing reform) & $\begin{array}{l}\text { Many experts argue that the low price of electricity explains why many } \\
\text { households in Uttar Pradesh villages do not have a reliable supply of } \\
\text { power. When the price is low, utilities do not invest in power plants be- } \\
\text { cause the low price does not cover the construction cost. According to these } \\
\text { experts, increasing the price of electricity could provide Uttar Pradesh vil- } \\
\text { lages with a more reliable supply of power. }\end{array}$ \\
\hline Treatment 2 (T2, fundamental rights) & $\begin{array}{l}\text { Many experts argue that access to electricity is a fundamental right for } \\
\text { the Indian people. According to these experts, the state is responsible for } \\
\text { providing everyone in Uttar Pradesh with electricity at an affordable cost. }\end{array}$ \\
\hline
\end{tabular}

Table 1: Overview of experimental conditions and the assigned treatment texts for the control group, the price reform treatment (T1), and the fundamental rights treatment (T2). 
Summary of outcome measures

\begin{tabular}{ll}
\hline Outcome group & Outcome measure \\
\hline Outcome 1 (no free provision) & $\begin{array}{l}\text { Government of Uttar Pradesh should not offer electricity to all rural house- } \\
\text { holds for free, because an electricity tariff that households pay would allow } \\
\text { a more reliable supply. }\end{array}$ \\
& $\begin{array}{l}\text { Government of Uttar Pradesh should invest in improved electricity gen- } \\
\text { eration capacity, even if doing so means that electricity tariffs have to be } \\
\text { increased. }\end{array}$ \\
& $\begin{array}{l}\text { Electricity markets in India should be privatized, so that the businessmen } \\
\text { who own power plants can freely choose electricity tariffs for their cus- }\end{array}$ \\
& tomers. \\
Outcome 3 (privatization) & Electricity is a commodity that the state should provide for all Indians. \\
& $\begin{array}{l}0=\text { Strongly disagree } \\
\text { Outcome } 4 \text { (state responsibility) }\end{array}$ \\
\hline Measurement & $2=$ Neutral \\
$3=$ Agree \\
$4=$ Strongly agree
\end{tabular}

Table 2: Summary of the four different outcome measures used in our survey experiment. 


\begin{tabular}{lccccc}
\hline & & & & & \\
& count & mean & sd & min & max \\
\hline Outcome 1 (no free provision) & 593 & 3.31 & 1.21 & 0.00 & 4.00 \\
Outcome 2 (higher prices) & 593 & 2.62 & 1.36 & 0.00 & 4.00 \\
Outcome 3 (privatization) & 593 & 0.82 & 1.33 & 0.00 & 4.00 \\
Outcome 4 (state responsibility) & 593 & 3.93 & 0.40 & 0.00 & 4.00 \\
Control group & 593 & 0.33 & 0.47 & 0.00 & 1.00 \\
Treatment 1 (pricing reform) & 593 & 0.33 & 0.47 & 0.00 & 1.00 \\
Treatment 2 (fundamental rights) & 593 & 0.33 & 0.47 & 0.00 & 1.00 \\
\hline
\end{tabular}

Table 3: Summary statistics. 
Correlation matrix

\begin{tabular}{|c|c|c|c|c|c|c|c|}
\hline & $(1)$ & $(2)$ & (3) & $(4)$ & (5) & (6) & (7) \\
\hline (1) Outcome 1 (no free provision) & 1.000 & & & & & & \\
\hline (2) Outcome 2 (higher prices) & $0.258^{* * *}$ & 1.000 & & & & & \\
\hline (3) Outcome 3 (privatization) & -0.027 & -0.027 & 1.000 & & & & \\
\hline (4) Outcome 4 (state responsibility) & 0.076 & 0.019 & -0.078 & 1.000 & & & \\
\hline (5) Control group & -0.025 & $-0.130^{* *}$ & -0.071 & -0.053 & 1.000 & & \\
\hline (6) Treatment 1 (pricing reform) & 0.043 & $0.105^{*}$ & 0.064 & 0.027 & $-0.501^{* * *}$ & 1.000 & \\
\hline (7) Treatment 2 (fundamental rights) & -0.018 & 0.025 & 0.007 & 0.026 & $-0.499^{* * *}$ & $-0.499^{* * *}$ & 1.000 \\
\hline
\end{tabular}

Table 4: Correlation matrix. 
Descriptive statistics and t-tests

\begin{tabular}{|c|c|c|c|c|c|c|c|c|}
\hline \multirow[b]{2}{*}{ Condition } & \multicolumn{2}{|c|}{ Outcome 1} & \multicolumn{2}{|c|}{ Outcome 2} & \multicolumn{2}{|c|}{ Outcome 3} & \multicolumn{2}{|c|}{ Outcome 4} \\
\hline & Mean & SD & Mean & $\mathrm{SD}$ & Mean & SD & Mean & SD \\
\hline Control & 3.26 & 1.28 & 2.37 & 1.41 & 0.69 & 1.20 & 3.90 & 0.51 \\
\hline Pricing reform treatment (T1) & 3.38 & 1.11 & 2.82 & 1.23 & 0.94 & 1.42 & 3.94 & 0.37 \\
\hline \multirow[t]{2}{*}{ Fundamental rights treatment (T2) } & 3.27 & 1.23 & 2.67 & 1.37 & 0.83 & 1.33 & 3.94 & 0.28 \\
\hline & \multicolumn{2}{|c|}{ Outcome 1} & \multicolumn{2}{|c|}{ Outcome 2} & \multicolumn{2}{|c|}{ Outcome 3} & \multicolumn{2}{|c|}{ Outcome 4} \\
\hline Tested groups & Difference & p-value & Difference & p-value & Difference & $\mathrm{p}$-value & Difference & p-value \\
\hline Control vs T1 & -0.12 & 0.337 & -0.45 & 0.000 & -0.25 & 0.057 & -0.04 & 0.318 \\
\hline Control vs T2 & -0.01 & 0.927 & -0.40 & 0.035 & -0.14 & 0.255 & & -0.040 .2833 \\
\hline T1 vs T2 & 0.11 & 0.377 & 0.15 & 0.245 & 0.11 & 0.442 & 0.00 & 0.993 \\
\hline
\end{tabular}

Table 5: Descriptive statistics and t-tests for all four outcome measures, separated by experimental condition. 
Outcome 1: UP Government should not provide electricity for free

\begin{tabular}{|c|c|c|c|c|}
\hline & \multicolumn{2}{|c|}{ OLS models } & \multicolumn{2}{|c|}{ Ordered probit } \\
\hline & $(1)$ & $(2)$ & (3) & $(4)$ \\
\hline Treatment 1 (pricing reform) & $\begin{array}{c}0.12 \\
(0.12)\end{array}$ & $\begin{array}{c}0.11 \\
(0.12)\end{array}$ & $\begin{array}{c}0.08 \\
(0.12)\end{array}$ & $\begin{array}{c}0.08 \\
(0.12)\end{array}$ \\
\hline Treatment 2 (fundamental rights) & $\begin{array}{c}0.01 \\
(0.13)\end{array}$ & $\begin{array}{c}0.00 \\
(0.13)\end{array}$ & $\begin{array}{l}-0.02 \\
(0.12)\end{array}$ & $\begin{array}{l}-0.02 \\
(0.12)\end{array}$ \\
\hline Interviewer fixed effects & No & Yes & No & Yes \\
\hline Village fixed effects & No & Yes & No & Yes \\
\hline $\begin{array}{l}\text { Observations } \\
R^{2}\end{array}$ & $\begin{array}{c}593 \\
0.002\end{array}$ & $\begin{array}{c}593 \\
0.005\end{array}$ & 593 & 593 \\
\hline Pseudo $R^{2}$ & & & 0.001 & 0.005 \\
\hline $\begin{array}{l}\text { Standard errors in parentheses } \\
\text { Dependent Variable: Outcome } 1 . \\
\text { Robust standard errors. } \\
{ }^{*} p<0.10,{ }^{* *} p<0.05,{ }^{* * *} p<0.0\end{array}$ & & & & \\
\hline
\end{tabular}

Table 6: Estimation results for OLS and ordered probit regressions for outcome measure 1. 
Outcome 2: UP Government should invest in electricity generation despite price increases

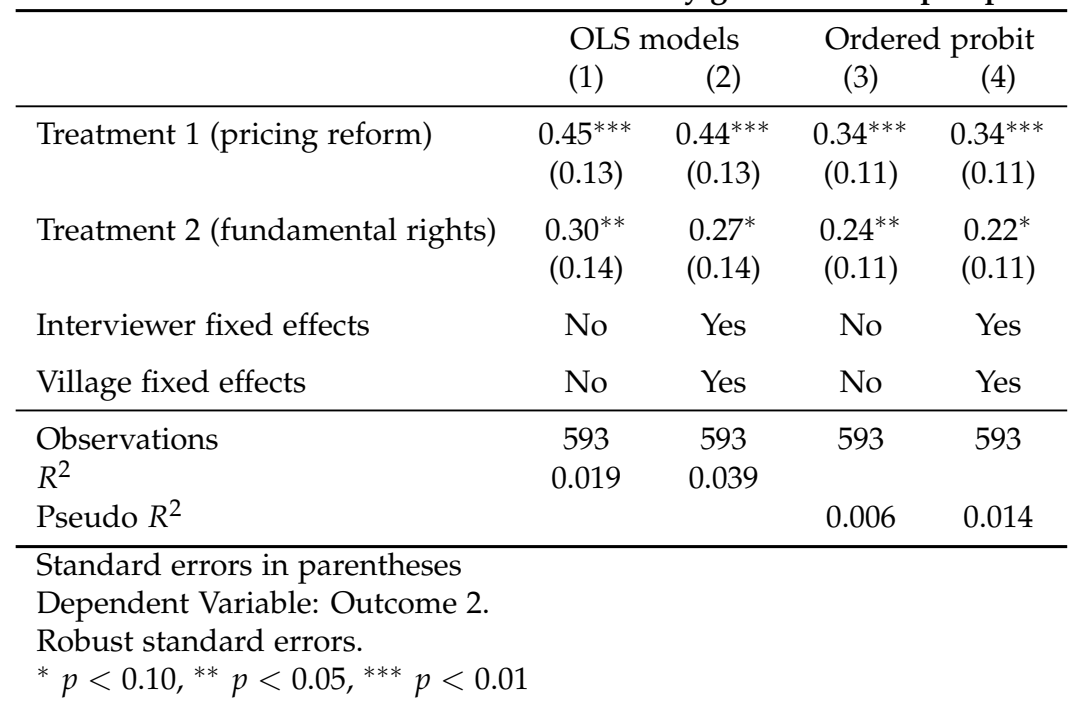

Table 7: Estimation results for OLS and ordered probit regressions for outcome measure 2. 
Outcome 3: Electricity markets should be privatized

\begin{tabular}{|c|c|c|c|c|}
\hline & \multicolumn{2}{|c|}{ OLS models } & \multicolumn{2}{|c|}{ Ordered probit } \\
\hline & $(1)$ & $(2)$ & & $(4)$ \\
\hline Treatment 1 (pricing reform) & $\begin{array}{l}0.25^{*} \\
(0.13)\end{array}$ & $\begin{array}{l}0.25^{*} \\
(0.13)\end{array}$ & $\begin{array}{l}0.23^{*} \\
(0.12)\end{array}$ & $\begin{array}{l}0.24^{*} \\
(0.12)\end{array}$ \\
\hline Treatment 2 (fundamental rights) & $\begin{array}{c}0.15 \\
(0.13)\end{array}$ & $\begin{array}{c}0.15 \\
(0.13)\end{array}$ & $\begin{array}{c}0.13 \\
(0.12)\end{array}$ & $\begin{array}{c}0.15 \\
(0.13)\end{array}$ \\
\hline Interviewer fixed effects & No & Yes & No & Yes \\
\hline Village fixed effects & No & Yes & No & Yes \\
\hline Observations & 593 & 593 & 593 & 593 \\
\hline$R^{2}$ & 0.006 & 0.068 & & \\
\hline Pseudo $R^{2}$ & & & 0.003 & 0.041 \\
\hline $\begin{array}{l}\text { Standard errors in parentheses } \\
\text { Dependent Variable: Outcome } 3 \text {. } \\
\text { Robust standard errors. } \\
{ }^{*} p<0.10,{ }^{* *} p<0.05,{ }^{* * *} p<0.0\end{array}$ & & & & \\
\hline
\end{tabular}

Table 8: Estimation results for OLS and ordered probit regressions for outcome measure 3. 
Outcome 4: Electricity is a commodity that should be provided by the state

\begin{tabular}{|c|c|c|c|c|}
\hline & \multicolumn{2}{|c|}{ OLS models } & \multicolumn{2}{|c|}{ Ordered probit } \\
\hline & $(1)$ & $(2)$ & (3) & $(4)$ \\
\hline Treatment 1 (pricing reform) & $\begin{array}{c}0.05 \\
(0.05)\end{array}$ & $\begin{array}{c}0.04 \\
(0.05)\end{array}$ & $\begin{array}{c}0.27 \\
(0.25)\end{array}$ & $\begin{array}{c}0.23 \\
(0.25)\end{array}$ \\
\hline Treatment 2 (fundamental rights) & $\begin{array}{c}0.05 \\
(0.04)\end{array}$ & $\begin{array}{c}0.05 \\
(0.04)\end{array}$ & $\begin{array}{c}0.10 \\
(0.22)\end{array}$ & $\begin{array}{c}0.08 \\
(0.21)\end{array}$ \\
\hline Interviewer fixed effects & No & Yes & No & Yes \\
\hline Village fixed effects & No & Yes & No & Yes \\
\hline $\begin{array}{l}\text { Observations } \\
R^{2}\end{array}$ & $\begin{array}{c}593 \\
0.003\end{array}$ & $\begin{array}{c}593 \\
0.021\end{array}$ & 593 & 593 \\
\hline Pseudo $R^{2}$ & & & 0.006 & 0.051 \\
\hline $\begin{array}{l}\text { Standard errors in parentheses } \\
\text { Dependent Variable: Outcome } 4 . \\
\text { Robust standard errors. } \\
{ }^{*} p<0.10,{ }^{* *} p<0.05,{ }^{* * *} p<0.0\end{array}$ & & & & \\
\hline
\end{tabular}

Table 9: Estimation results for OLS and ordered probit regressions for outcome measure 4. 
Linear probability models for Santhakumar dataset

\begin{tabular}{|c|c|c|c|c|c|c|}
\hline & \multicolumn{3}{|c|}{ OLS models } & \multicolumn{3}{|c|}{ Logit models } \\
\hline & (1) & (2) & (3) & (4) & (5) & (6) \\
\hline Education & $\begin{array}{c}0.0047^{* * *} \\
(0.0014)\end{array}$ & $\begin{array}{c}0.0073^{* * *} \\
(0.0013)\end{array}$ & $\begin{array}{c}0.0043^{* * *} \\
(0.0015)\end{array}$ & $\begin{array}{c}0.0200^{* * * *} \\
(0.0059)\end{array}$ & $\begin{array}{c}0.0478^{* * *} \\
(0.0088)\end{array}$ & $\begin{array}{c}0.0240^{* *} \\
(0.0104)\end{array}$ \\
\hline Age & & & $\begin{array}{l}0.0009^{*} \\
(0.0004)\end{array}$ & & & $\begin{array}{l}0.0051^{*} \\
(0.0031)\end{array}$ \\
\hline Male dummy & & & $\begin{array}{c}0.0283^{* *} \\
(0.0138)\end{array}$ & & & $\begin{array}{c}0.2089^{* *} \\
(0.0991)\end{array}$ \\
\hline Agriculture & & & $\begin{array}{l}0.0296^{*} \\
(0.0156)\end{array}$ & & & $\begin{array}{c}0.2224^{* *} \\
(0.1123)\end{array}$ \\
\hline Subsidy payments & & & $\begin{array}{c}-0.0282 \\
(0.0196)\end{array}$ & & & $\begin{array}{c}-0.1943 \\
(0.1210)\end{array}$ \\
\hline Household assets & & & $\begin{array}{c}0.0265^{* * *} \\
(0.0038)\end{array}$ & & & $\begin{array}{c}0.1855^{* * *} \\
(0.0276)\end{array}$ \\
\hline District fixed effects & No & Yes & Yes & No & Yes & Yes \\
\hline $\begin{array}{l}\text { Observations } \\
R^{2}\end{array}$ & $\begin{array}{l}5004 \\
0,002\end{array}$ & $\begin{array}{l}5004 \\
0.384\end{array}$ & $\begin{array}{l}4973 \\
0.393\end{array}$ & 5004 & 4914 & 4883 \\
\hline Pseudo $R^{2}$ & & & & 0.002 & 0.307 & 0.319 \\
\hline
\end{tabular}

Table 10: Estimation results for OLS and logit regressions using the Santhakumar (2008) dataset. 